\title{
Evaluation of Road Traffic Accidents (RTAs) on Hyderabad Karachi M-9 Motorway Section
}

\author{
Amir Detho \\ Energy \& Environment Department \\ Quaid-e-Awam University of \\ Engineering, Science \& Technology \\ Nawabshah, Pakistan \\ aamir_detho@yahoo.com
}

\author{
Saleem Raza Samo \\ Energy \& Environment Department \\ Quaid-e-Awam University of \\ Engineering, Science \& Technology \\ Nawabshah, Pakistan \\ sfaizsamo@yahoo.com
}

\author{
Kishan Chand Mukwana \\ Energy \& Environment Department \\ Quaid-e-Awam University of \\ Engineering, Science \& Technology \\ Nawabshah, Pakistan \\ mukwana_99@yahoo.com
}

\author{
Kamran Ahmed Samo \\ Electrical Engineering Department \\ Quaid-e-Awam University College of \\ Engineering, Science \& Technology \\ Larkana, Pakistan \\ kamransamo2@gmail.com
}

\author{
Asif Ali Siyal \\ Energy \& Environment Department \\ Quaid-e-Awam University of \\ Engineering, Science \& Technology \\ Nawabshah, Pakistan \\ asifsiya12007@quest.edu.pk
}

\begin{abstract}
Pakistan is a developing country and its development depends upon its transports facilities. This paper describes the findings of a survey for the evaluation of road traffic accidents (RTAs) that focused on the Hyderabad-Karachi M-9 Motorway section. The objectives of the survey are the collection the data of traffic accidents including the human and property losses and the evaluation of RTAs causes. During a two year period (i.e. 2015 and 2016) it was revealed that 145 RTAs occurred on the motorway. In those RTAs, 109 persons died and 293 got injured and 251 vehicles were damaged. High risk percentages were recorded for both pedestrian and vehicle users.
\end{abstract} RTAs

Keywords-road traffic accidents; RTAs; evaluation; causes of

\section{INTRODUCTION}

In Pakistan, highways were initially used as feeders to railways that were the main transport utility for long distances and goods. Nowadays however, the use of highways has increased and their length has expanded from $249,972 \mathrm{~km}$ (in $2000-01$ ) to $263,356 \mathrm{~km}$ (in 2015-16). A similar increase is recorded on the number of vehicles, from 4,701,600 (in 200001) to $17,317,600$ (in 2015-16) [1]. The maintenance and construction of roads in Pakistan falls under the State Government and National Highway Department. For this research, an extensive literature survey was carried out to determine and learn the past findings in the area of RTAs. Authors in [2] state that road studies and road safety learning are very necessary, especially for those who are often directly involved in RTA injuries, for example students. They introduced the road safety concept for pre schooling students through animal world stories. It is concluded that it is needed to improve the driving skills, to adopt strict rules and regulations, to adapt more comprehensive rules and to use more traffic controlling devices. During the issuance of driving license to public transport drivers, first aid training must be undertaken.

Author in [3] states that the RTAs are the 8th main cause of deaths in the world. According to WHO (2004), RTAs will become the 3rd main cause of death by the year 2020, if not controlled properly. Furthermore, the available data is not trustworthy due to under reporting. Anyhow, RTAs are one of leading causes of death and injury worldwide. Author in [4] states that huge losses due to road accident were reported in Tanzania. In 1994, the (high) cost of accident losses was estimated and it was established that it kept increasing. Road safety issues are now been under consideration by the Tanzania government. The speed limit of the buses has been controlled. However, the RTAs still keep increasing. Therefore, a research was conducted by Swedish International Development Cooperation Agency (SIDA)/SAREC with the collaboration of the Department of Statistics at the University of Dar es Salaam. In this research, a survey was conducted to investigate the possible reasons of RTAs. In the survey, people (including drivers of buses, motor cyclist and pedestrians) were asked their opinion regarding the reasons on RTAs. It was identified that the mistakes done by the drivers were the main reason of the accidents. It was concluded that drivers should be welltrained before they are allowed to drive on the road.

Authors in [5] remind that accidents cause not only economic losses but also intangible consequences such as pain, grief etc. The increasing number of cars and other vehicles is one of the major causes of RTAs during the last two decades. For reducing the impacts of RTAs, many safety programs have been organized. They concluded that for reducing the number of accidents, the safety programs of developed countries should be implemented in their country. Author in [6] states that a little amount of research has been conducted on the road 
accidents in India which is the second-largest populated country in the world. To make the policies workable and effective, the safety plan must be based on the local research and evidence. These plans must be designed to suit the local environment and circumstances. Authors in [7] state that the complexity of the flow pattern of the vehicles on the highways is the major reason of the accidents. The rate of the road accidents has increased from 2001 to 2011 . It is estimated that 12 persons per 100 accidents were killed in 2011, whereas 7 were killed in 2001. Because of damaged roads in rural areas, the road accidents are more likely to happen. Author in [8] states that road accidents are considered as human tragedy because of deaths, injuries and loss of income. Extensive research has been conducted to investigate the causes of the road accidents. However, the road safety programs are still not as per standard as reveled by the data. In 2010, ten road accidents in every minute have been reported and one death due to road accidents occurred in every 4 minutes. It is difficult for the government to solve this problem alone.

Authors in [9] dealt with districts with repeating accidents, Ernakulam and Alappuzha. With the use of weighted severity index (WSI) method, ten spots in Ernakulam and six spots in Alappuzha was selected for data collection and analysis. On the basis of data collection, Kalamassery and Mulamthuruthy in Ernakulam and Kalavoor in Alappuzha, were the most repeated accident locations and valuable and effective measures were taken and improved the transport system in the district. Author in [10] collected RTAs data in Kerala state of India from 2010 to 2016 . He concluded that 12 persons were killed per 100 accidents in 2016. Nowadays, in modern societies, road traffic safeties have become a major concerning issue. In Pakistan, the population increases along with road traffic control problems something that is very common in all country's big cities. Day by day the road traffic, the RTAs increase, the roads become more dangerous day by day. The fatalities and injuries due RTAs have a great impact on socioeconomic development and societal well being. According to World Health organization [11], each year an estimated 1.2 millions of people lose their lives and around 50 millions got injured worldwide due to RTAs. RTAs are caused by technical faults, dangerous driving, bad weather, bad road design and signage. However, in terms of automobile technology safety has been achieved progress. In view of the aforementioned issues, the key objectives of this study work are:

1. To survey the project area in terms of RTAs, loss of lives and vehicles.

2. To evaluate the causes of the occurrence of RTAs.

\section{RESEARCH METHODOLOGY}

In order to achieve the mentioned objectives, a survey on Hyderabad-Karachi highway was conducted for two years (2015 and 2016). The data source was the National Highway \& Motorway police (NH\&MP). The two year RTAs data include the total number of accidents (i.e, fatal and non-fatal), the number of people who died and got injured anb the number of damaged vehicles.

\section{RESULTS AND DISCUSSION}

\section{A. Fatal and Non-Fatal Accident During 2015 and 2016}

The total number of reported accidents from the data of RTAs during 2015 and 2016 are categorized as fatal and nonfatal. The road accidents in which death occurs are called fatal accidents and non-fatal accidents are those in which no of life happens. After analyzing the data, it was found that 85 accidents were reported from January to December, 2015. Among these, 41 were classified as fatal and the rest as nonfatal. With 60 accidents in the year 2016, 31 and 29 were reported as fatal and non-fatal, respectively. The fatal and nonfatal number of accidents during the years 2015 and 2016 are summarized in Table I.

TABLE I. RTAs DURING 2015 AND 2016

\begin{tabular}{|c|c|c|c|}
\hline Year & Total accidents & Fatal & Non-fatal \\
\hline 2015 & 85 & 41 & 44 \\
\hline 2016 & 60 & 31 & 29 \\
\hline
\end{tabular}

\section{B. Analysis of RTAs Occured During 2015 and 2016}

As mentioned above the total numbers of RTAs reported are 85 and 60 in years 2015 and 2016, respectively. The data collected were further sub-divided depending on the number of deaths, the number of injured and the number of damaged vehicles.

\section{1) Number of Deaths}

Figure 1 shows the number of deaths reported in fatal RTAs during 2015 and 2016. The horizontal axis shows the months while vertical axis represents the number of deaths. It can be seen from the Figure that 56 and 53 deaths occurred in 2015 and 2016, respectively. In 2015, the maximum number of deaths accrued in February. But in April, June and November only one loss of life was reported. In the following year, the maximum (i.e. 16) number of deaths occurred in April. However, no death occurred in last two months of the year. Comparing the years 2015 and 2016, the total number of deaths are more or less same.

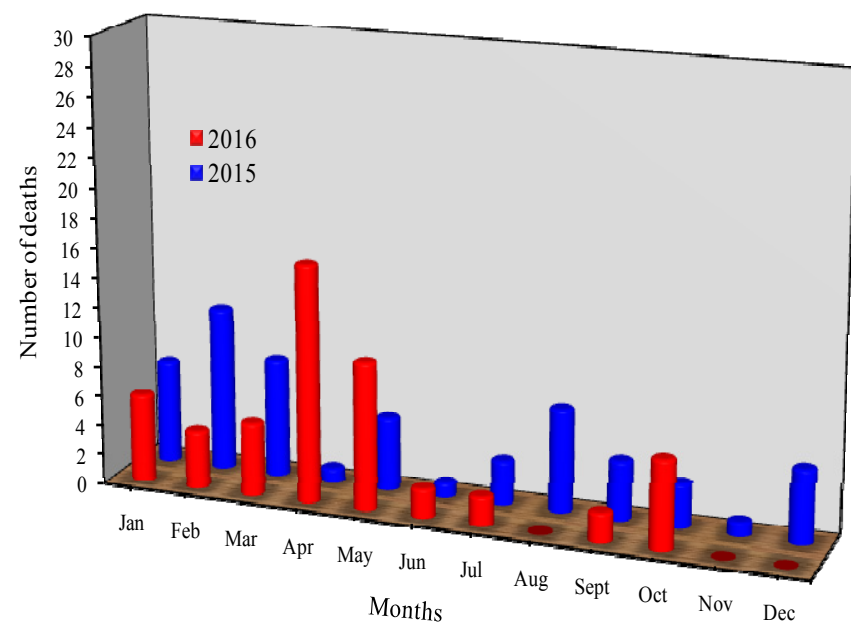

Fig. 1. Number of deaths in RTAs reported in 2015 and 2016 


\section{2) Number of Injuries}

Figure 2 illustrates the number of injured persons reported in non-fatal RTAs during year 2015 and 2016. It can be observed from the Figure that 170 and 123 number of injuries occurred in 2015 and 2016, respectively. In 2015, the maximum number of injured persons was reported in October. The minimum number of injured persons (i.e. 2) was reported in April. Among 123 reported injured persons in 2016, the highest number (i.e. 28) of injuries was documented in January. Two injuries (which is the least number for 2016) were reported in June and November. Among the 24 months 2015 and 2016, the RTAs' data revealed that the maximum number of injuries occurred in October of 2015.

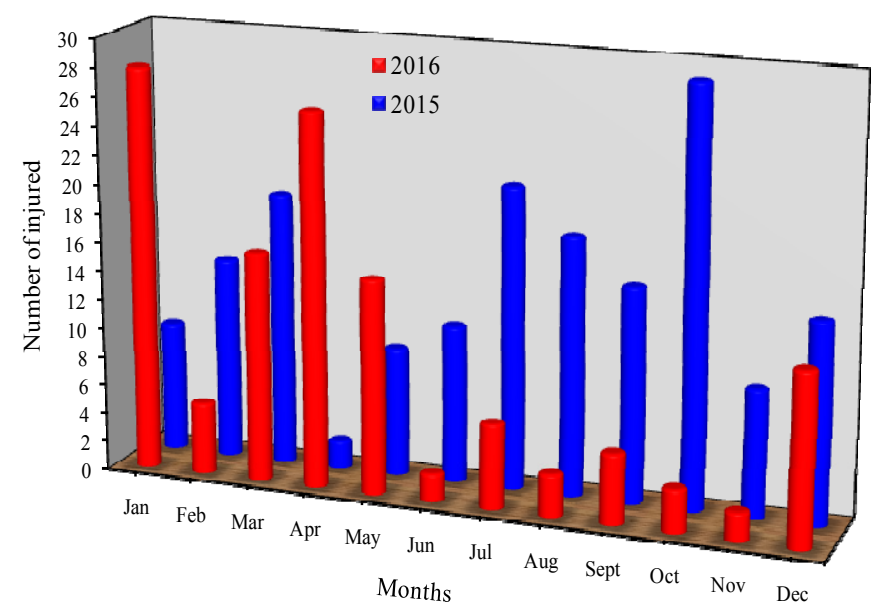

Fig. 2. Number of injured persons in RTAs reportd in 2015 and 2016

\section{3) Number of Damaged Vehicles}

Besides the loss of human lives, it is necessary to look at the economic loss caused by accidents. For this reason the number of damaged vehicles was documented in the collected RTAs data. Figure 3 shows the number of damaged vehicles during each month of the years 2015 and 2016. It can be seen that the numbers of damaged vehicles were documented as 141 and 110 in 2015 and 2016 respectively. In 2015, the maximum number of damaged vehicles (i.e. 18) was reported in July. The minimum was in February with five damaged vehicles reported. In the following year (i.e. 2016), the maximum (i.e. 27) and minimum (i.e. 1) number of damaged vehicles were reported in April July respectively. It is evident that the loss of human lives and economic loss the maximum in April of 2016.

\section{4) Causes of RTAs on highway}

The causes of accidents were also documented. Five different causes were identified at the accidents sites. These are (1) careless driving, (2) bursting of tyres of vehicles, (3) brake failure of vehicle, (4) bad road conditions and (5) pedestrian crossing. Data revealed that careless driving is the major cause of the RTAs on the motorway. Due to this reason, 29 and 19 people died in 2015 and 2016 respectively and total 293 people got injured in both the reported years. As for the economic loss 93 vehicles were damaged in 2015 and 110 vehicles were damaged are 2016. Besides human error while driving, the vehicle condition was another one of the reasons of RTAs. Tire bursting and brake failure belong in this category. Because of brake failure and tire bursting 48 deaths occurred in the reported period while 110 people got injured and 66 vehicles got damaged. The condition of the road/highway has been recognized as another reason for RTAs. Data have shown that 16 people died in accidents due to bad road conditions. Furthermore, 40 people got injured and 34 vehicles were damaged in the accidents which occurred due to bad road conditions. The numbers of loss of human lives and vehicles damaged in RTAs due to different reasons are summarized in Table II.

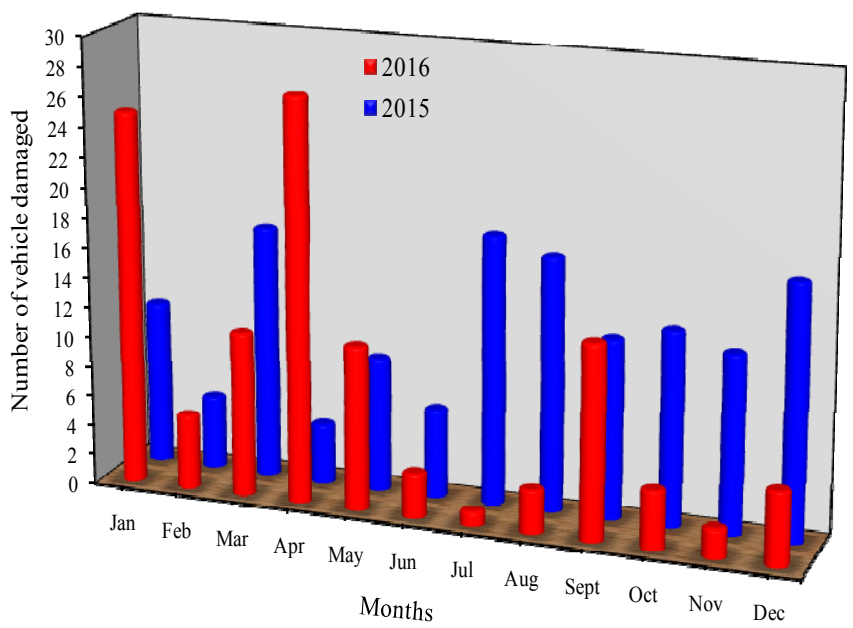

Fig. 3. Number of reported damaged vehicles in RTAs in 2015 and 2016

TABLE II.

HUMAN LIVES/ECONOMICAL LOSS AND THEIR CAUSES

\begin{tabular}{|c|c|c|c|c|c|c|c|}
\hline \multirow[b]{2}{*}{ 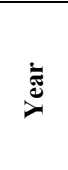 } & \multirow{2}{*}{ 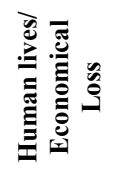 } & \multirow[b]{2}{*}{ 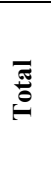 } & \multicolumn{5}{|c|}{ CAUSES } \\
\hline & & & 酊 & 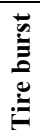 & $\frac{\mathscr{D}}{\mathbb{J}}$ & 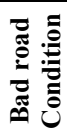 & 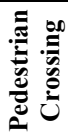 \\
\hline \multirow{3}{*}{2015} & Deaths & 56 & 27 & 16 & 9 & 3 & 1 \\
\hline & Injuries & 170 & 90 & 36 & 28 & 16 & 0 \\
\hline & $\begin{array}{l}\text { Vehicles } \\
\text { damaged }\end{array}$ & 141 & 93 & 19 & 20 & 4 & 5 \\
\hline \multirow{3}{*}{2016} & Deaths & 53 & 19 & 7 & 14 & 13 & 0 \\
\hline & Injuries & 123 & 50 & 24 & 22 & 24 & 3 \\
\hline & $\begin{array}{l}\text { Vehicles } \\
\text { damaged }\end{array}$ & 110 & 52 & 12 & 15 & 30 & 1 \\
\hline
\end{tabular}

\section{SUMMARY AND CONCLUSIONS}

Based on accident data collected from January, 2015 to December, 2016 on M9 Motorway, the following conclusions are drawn:

1. The findings indicate that human error (careless driving \& pedestrian crossing), mechanical fault (tire burst and brake failure) and bad road condition were the major causes for the Motorway RTAs. 
2. In 2015 , the number of accidents (in percentage) due to careless driving, tire burst, brake failure, pedestrian crossing and bad road condition are 59, 20,15, 1 and 5, respectively.

3. In 2016, the number of accidents (in percentage) due to careless driving, tire burst, brake failure, pedestrian crossing and bad road condition are 53, 15, 16, 3 and 13, respectively.

4. Based on collected accident data, 109 human lives were lost and 293 persons were reported as injured. In addition, 251vehicles were damaged.

\section{ACKNOWLEDGMENT}

The authors are grateful to the Quaid-e-Awam University of Engineering, Science and Technology, Nawabshah for providing the research facilities.

\section{REFERENCES}

[1] Government of Pakistan, Ministry of Finance, Pakistan Economic Survey 2015-16, available at: http://www.finance.gov.pk/survey_ 1516.html

[2] N. Jha, D. K. Srinivasa, G. Roy, S. Jagdish, "Epidemiological Study of Road Traffic Accident Cases: A study from South India”, Indian Journal of Community Medicine, Vol. 29, No. 1, pp. 20-24, 2004

[3] G. Al-Haji, Road Safety Development Index: Theory, Philosophy and Practice, PhD Thesis, Linkoping University of Technology, 2007

[4] R. R. Akkarro, "Peoples Opinion on the Causes of Road Accidents in selected places of Tanzania", European Journal of Social Sciences, Vol. 9, No. 4, pp.615-626, 2009

[5] B. B. Pillai, K. Joseph, "Causes and consequences of road accidents in Kerala", International Journal of Research in IT \& Management, Vol. 1, pp. 83-95, 2011

[6] M. M. Ruikar, "National Statistics on Road Traffic Accidents in India", Journal of Orthopedics, Traumatology and Rehabilitation, Vol. 6, No. 1, 2013

[7] B. V. Sreekumar, V. Sreedevi, "Impact of Road Accidents in Kerala During 2001 to 2011-A Case Study", Singaporean Journal of Scientific Research, Vol. 6, No. 1, pp. 51-57, 2014

[8] P. Deshpande, "Road Safety and Accident Prevention in India", International Journal of Advanced Engineering Technology, Vol. 5, No. 2, pp. 64-68, 2014

[9] L. Isen, A. Shibu, M. S. Saran, "Identification and Analysis of Black spots using Geographic information system", International Journal of Innovative Research in Science, Engineering \& Technology, Vol. 2, No. 1, pp.131-139, 2013

[10] A. Chand, "A case study of raod accidents in Kerala during 2010 to 2016", International Journal of Innovative Research in Science, Engineering \& Technology, Vol. 6, No. 4, pp. 199-203, 2017

[11] World Health Organization(WHO), Word report on road traffic injury preventation: Summary, World Health Organization, 2004 